\title{
miR-625-5p suppresses inflammatory responses by targeting AKT2 in human bronchial epithelial cells
}

\author{
FEN-HONG QIAN* , XIA DENG* , QIONG-XIN ZHUANG, BIN WEI and DAN-DAN ZHENG \\ Department of Respiratory Medicine, Affiliated Hospital of Jiangsu University, Zhenjiang, Jiangsu 212000, P.R. China
}

Received December 16, 2017; Accepted October 2, 2018

DOI: $10.3892 / \mathrm{mmr} .2019 .9817$

\begin{abstract}
Asthma is a common chronic inflammatory airway disease; however, whether microRNAs (miRs) could be used in the treatment of asthma remains unclear. The aim of the present study was to investigate the role of miR-625-5p in the inflammatory response of human bronchial epithelial cells (HBECs). Inflammation in the HBEC line, 16HBEC, was induced using different concentrations of lipopolysaccharide (LPS), which demonstrated that $1 \mu \mathrm{g} / \mathrm{ml}$ LPS was an appropriate concentration for further experiments. The association between protein kinase B2 (AKT2) and miR-625-5p was verified using a luciferase reporter assay. LPS was added to 16HBECs following the administration of miR-625-5p mimics or miR-625-5p inhibitors, and cells with silenced or overexpressed AKT2 levels. miR-625-5p was expressed at a high level in LPS-activated 16HBECs. Overexpression of miR-625-5p inhibited interleukin (IL)-6 and tumor necrosis factor (TNF) $\alpha$ secretion in 16HBECs. Inhibition of miR-625-5p enhanced LPS-induced IL- 6 and TNF- $\alpha$ secretion. miR-625-5p negatively regulated the expression of AKT2 in 16HBECs. A dual-luciferase reporter assay system confirmed that miR-625-5p directly targeted the 3'untranslated region of $A K T 2$. Transfection with a small interfering RNA against $A K T 2$ inhibited inhibitor of $\kappa \mathrm{B}$ phosphorylation. In brief, miR-625-5p may protect LPS-induced HBECs by targeting $A K T 2$ and inhibiting the nuclear factor- $\kappa \mathrm{B}$ signaling pathway. Therefore, miR-625-5p may function as an inhibitor of asthma airway inflammation in HBECs by targeting AKT2.
\end{abstract}

\section{Introduction}

Asthma is a heterogeneous disease that involves an imbalance of airway inflammation. The airway epithelium is not only the

Correspondence to: Professor Fen-Hong Qian, Department of Respiratory Medicine, Affiliated Hospital of Jiangsu University, 438 Jiefang Road, Zhenjiang, Jiangsu 212000, P.R. China

E-mail: zhaoqian604@126.com

*Contributed equally

Key words: microRNA-625-5p, protein kinase B, bronchial epithelial cells, inflammation first anatomical barrier to airborne pathogens and stimuli, but it is also capable of mounting a number of immune responses (1). When an inflammatory stimulus activates epithelial cells, a series of inflammatory cascades, including innate and adaptive immune responses, are initiated (2). These important functions of airway epithelial cells make them potential targets to treat asthma.

The protein kinase B (AKT) family of kinases (AKT1, -2 and -3) has a key role in the inflammatory response. However, it is not clear which of the AKT family, if any, is a major player in asthmatic airway inflammation. In our recent experiments, it was observed that specific variants in the 3'untranslated region (UTR) of $A K T 2$ may influence susceptibility to asthma (unpublished data); however, the details of the involvement of AKT2 activity are unknown.

MicroRNAs (miRs) are short noncoding RNAs that pair with the 3'UTR of target mRNAs to regulate gene expression through mRNA degradation or translational repression (3). An increasing body of evidence has suggested that dysregulation of the expression of miRs is correlated with various physiological and pathological processes $(4)$, for example, in asthma $(5,6)$. Recent studies have demonstrated the regulation of miR gene expression in bronchial epithelial cells (BECs) (6-9). The expression levels of miR-18A, $-27 \mathrm{~A},-128,-155$ and $-181 \mathrm{~b}-5 \mathrm{p}$ in asthmatic BECs decreased (6), while the level of miR-19a in the epithelia of patients with severe asthma increased $(7,8)$. A functional study demonstrated that miR-19a inhibits the proliferation of severe asthmatic BECs by targeting transforming growth factor- $\beta$ receptor 2 mRNA (9). miR-181b-5p affects eosinophilic inflammation by targeting the gene encoding secreted phosphoprotein 1 (8). For other miRs, including miR-18A, -27A, -128 and -155, no consensus miR binding sites were observed in the 3 'UTRs of the target genes (5).

miR-625 is a multifunctional $\mathrm{miR}$ that has been implicated in carcinogenesis, including colorectal adenocarcinoma (10), malignant pleural mesothelioma (11) and hepatocellular cancer (12). To date, only one study has focused on the miR-625/AKT2 axis in increasing the chemosensitivity of glioma (13). In terms of its association with asthma, miR-625-5p is significantly downregulated in pediatric asthma and targets the gene encoding estrogen receptor 1 (14). This suggested a role for this $\mathrm{miR}$ in the pathogenesis of allergic diseases. Therefore, the present study was designed to investigate the novel characteristics of miR-625 in the potential pathogenic mechanism of asthma. It was hypothesized that 
miR-625-5p may alter the inflammatory responses in human BECs (HBECs) by targeting the AKT2 signaling pathway.

\section{Materials and methods}

Cell culture. The cell lines (16HBECs and A549 cells) were purchased from the Type Culture Collection of the Chinese Academy of Science (Shanghai, China) and grown in Dulbecco's modified Eagle's medium (DMEM; Gibco ${ }^{\circledR}$; Thermo Fisher Scientific, Inc., Waltham, MA, USA) with 10\% fetal bovine serum (Sigma-Aldrich; Merck KGaA, Darmstadt, Germany) and $100 \mu \mathrm{g} / \mathrm{ml}$ streptomycin (Beyotime Institute of Biotechnology, Shanghai, China) at $37^{\circ} \mathrm{C}$ in $5 \% \mathrm{CO}_{2}$.

MTT assay. An MTT assay (Beyotime Institute of Biotechnology, Shanghai, China) was used to measure cell viability. The cells were seeded in $96-$ well plates with $1-3 \times 10^{4}$ cells in a volume of $200 \mu \mathrm{l}$ in each well and incubated for $24 \mathrm{~h}$. The cells were then incubated with different concentrations $(0,0.1,1,10$ and $100 \mu \mathrm{g} / \mathrm{ml})$ of lipopolysaccharide (LPS; Sigma-Aldrich; Merck KgaA) for $12 \mathrm{~h}$ at $37^{\circ} \mathrm{C}$. The supernatant was removed from the cells and added to medium with $5 \mathrm{mg} / \mathrm{ml}$ MTT for $4 \mathrm{~h}$. The medium was discarded and $100 \mu 1$ solubilization solution (included in MTT assay kit) was added to dissolve the formazan crystals. The absorbance was measured at a wavelength of $570 \mathrm{~nm}$ using a Multiskan Spectrum instrument (Thermo Fisher Scientific, Inc.). The ratio of the absorbance of the treatment group to that of the control group represented the viability of the cells.

Transfection. Cells seeded in 6-well plates at a density of $1 \times 10^{6}$ cells/well were transfected with an miR-625-5p mimic (5'-AGGGGGAAAGUUCUAUAGUCC-3'), miR-625-5p inhibitor (5'-AGGGGGAAAGUUCUAUAGUCC-3'), a negative control miR (5'-UUCUCCGAACGUGUCACG U-3') and an inhibitor negative control (5'-AAGAGGCUU GCACAGUGCA-3'), which were obtained from Guangzhou Ribobio Co., Ltd., (Guangzhou, China); and with the AKT2 small interfering RNA (si-AKT2; sense, 5'-GCUCCUUCA UUGGGUACAATT-3'), scrambled negative control (5'-UUC UCCGAACGUGUCACGUTT-3'), the AKT2 overexpression plasmid (v-AKT2), and control vector, which were obtained from Shanghai GenePharma Co., Ltd., (Shanghai, China). miR-625-5p mimic (75 pmol/well) or miR-625-5p inhibitors (120 pmol/well) and their controls (corresponding concentration) were mixed with $5 \mu$ l Lipofectamine $2000^{\mathrm{TM}}$ (Thermo Fisher Scientific, Inc.), then incubated with $1 \times 10^{6}$ cells in 6-well plates. Similarly, si-AKT2 (75 pmol/well) or v-AKT2 $\left(2.5 \mu \mathrm{g} /\right.$ well) were mixed with $5 \mu \mathrm{l}$ Lipofectamine $2000^{\mathrm{TM}}$ and transfected into cells. Following $6 \mathrm{~h}$, Opti-Minimum Essential Medium $^{\mathrm{TM}}$ (Gibco; Thermo Fisher Scientific, Inc.) was discarded and fresh DMEM was added. The cells were incubated for another $24 \mathrm{~h}$, then washed three times with cold PBS and used for protein extraction immediately after cell collection.

ELISA. The cells seeded in 6-well plates at a density of $2 \times 10^{5}$ cells/well were cultured with the miR-625-5p mimic or miR-625-5p inhibitor with LPS $(1 \mu \mathrm{g} / \mathrm{ml})$ for $24 \mathrm{~h}$ at $37^{\circ} \mathrm{C}$. The cells and the culture supernatants were collected separately.
Table I. Quantitative polymerase chain reaction primers.

\begin{tabular}{lll}
\hline Gene & Primer & \multicolumn{1}{c}{ Sequence (5'-3') } \\
\hline TNF- $\alpha$ & Forward & CTCCTCACCCACACCATCA \\
& Reverse & GGAAGACCCCTCCCAGATAG \\
IL-6 & Forward & TTCGGTCCAGTTGCCTTCT \\
& Reverse & GGTGAGTGGCTGTCTGTGTG \\
$\beta$-actin & Forward & AGAGCTACGAGCTGCCTGAC \\
& Reverse & AGCACTGTGTTGGCGTACAG \\
U6 & Forward & CTCGCTTCGGCAGCACA \\
& Reverse & AACGCTTCACGAATTTGCT
\end{tabular}

IL, interleukin; TNF, tumor necrosis factor.

The levels of interleukin (IL)-6 (cat. no. D6050) and tumor necrosis factor- $\alpha$ (TNF- $\alpha$ ) (cat. no. DTA00D) in the supernatant released from 16HBECs were evaluated using ELISA kits (R\&D Systems, Inc., Minneapolis, MN, USA).

Reverse transcription-quantitative polymerase chain reaction (RT-qPCR). Total RNA from cultured 16HBECs and isolated using RNAiso Plus (Takara Biotechnology Co., Ltd., Dalian, China). PrimeScript reagents (Takara Bio Inc., Otsu, Japan) were used to synthesize cDNA at $37^{\circ} \mathrm{C}$ for $15 \mathrm{~min}$ followed by RT inactivation at $85^{\circ} \mathrm{C}$ for $5 \mathrm{sec}$. RT-qPCR was completed using a MxPRO 3000 real-time PCR system and SYBR $^{\circledR}$ Premix Ex Taq ${ }^{\mathrm{TM}}$ (TliRNaseH Plus; cat. no. RR420) (Takara Bio, Inc.); $0.8 \mu 1$ primers, $0.4 \mu 1$ ROX Reference Dye or Dye II $2 \mu \mathrm{lcDNA}$ and $8 \mu \mathrm{l} \mathrm{dH}_{2} \mathrm{O}$ were employed and the reaction mixture was made up to $20 \mu 1$. The procedure was implemented according to the manufacturer's protocols. The thermocycling conditions were as follows: Denaturation at $95^{\circ} \mathrm{C}$ was for $5 \mathrm{sec}$, annealing at $60^{\circ} \mathrm{C}$ was for $34 \mathrm{sec}$ min and extension at $60^{\circ} \mathrm{C}$ was for $1 \mathrm{~min}$. The primers used are presented in Table I. The $2^{-\Delta \Delta C q}$ relative quantification method was used to calculate the mean fold expression difference between the groups (15).

Western blotting. Proteins from 16HBECs were prepared routinely using radioimmunoprecipitation lysis buffer (cat no. P0013C) and phenylmethanesulfonylfluoride (cat no: ST506) kit (Beyotime Institute of Biotechnology) according to the manufacturer's protocol. A bicinchoninic assay kit (Beyotime Institute of Biotechnology) was used to quantify the protein levels. Total protein extracts $(40 \mu \mathrm{g})$ were separated by $10 \%$ SDS-PAGE and transferred onto a polyvinylidene fluoride membrane (EMD Millipore, Billerica, MA, USA). Membranes were blocked in 5\% bovine serum albumin (Beyotime Institute of Biotechnology; cat no. P0007) for $1 \mathrm{~h}$ at room temperature, then incubated with primary antibodies (1:1,000; Cell Signaling Technology, Inc., Danvers, MA, USA). The primary antibodies were as follows: P-AKT2 (cat. no. 8599), AKT2 (cat. no. 2964), P-IкB $\alpha$ (cat. no. 9246), $\beta$-actin (cat. no. 4970) overnight at $4^{\circ} \mathrm{C}$, followed by incubation with horseradish peroxidase-conjugated secondary antibodies (1:3,000; cat. nos. 7076 and 7074; Cell Signaling Technology, 

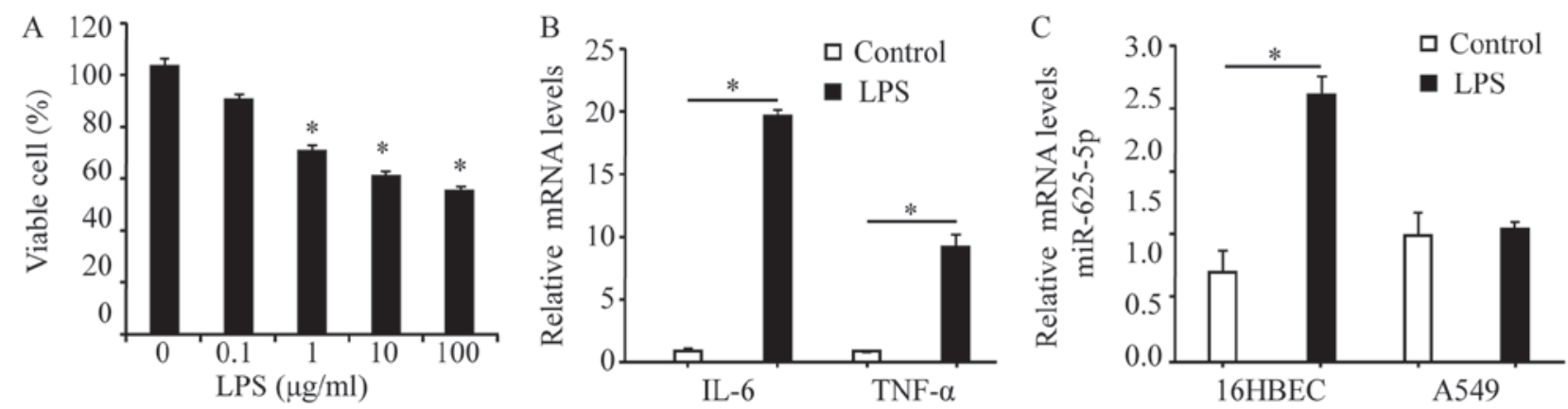

Figure 1. Cell viability and assessment of cytokine mRNA expression. (A) The MTT assay was conducted to measure 16HBEC viability induced by LPS 16HBECs were seeded with various levels of LPS $(0-100 \mu \mathrm{g} / \mathrm{ml})$ for $24 \mathrm{~h}$ while PBS treated cells served as the control. "P $<0.05 \mathrm{vs.} 0 \mu \mathrm{g} / \mathrm{ml}$ LPS. (B) The levels of IL- 6 and TNF- $\alpha$ mRNA were elevated following LPS (1 $\mu \mathrm{g} / \mathrm{ml})$ treated by RT-qPCR. (C) miR-625-5p expression was detected by RT-qPCR in $16 \mathrm{HBEC}$ and A549 cells, and normalized with U6 RNA. "P<0.05, as indicated. LPS, lipopolysaccharide; miR, microRNA; TNF- $\alpha$, tumor necrosis factor- $\alpha$; IL, interleukin; RT-qPCR, reverse transcription-quantitative polymerase chain reaction; HBEC, human bronchial epithelial cell.

Inc.) for $2 \mathrm{~h}$ at room temperature. The immunoreactive proteins on the blots were scanned by FluorChem FC3 (Protein Simple, San Jose, CA, USA).

Plasmid construction. The AKT2 3'UTR was amplified using human DNA as a template. The wild-type (WT) 3'UTR of $A K T 2$ was inserted into the luciferase gene in the pMIR-Report vector (Promega Corporation, Madison, WI, USA; cat. no. E1330) and termed pMIR-AKT2-WT. The primers used to amplify the wild-type sequence were: 5'-CGA GCTCGGGAGGGGCCTGAAGAAGAACT-3' forward, and 5'-CCAAGCTTCCTGGGCTTACTGGAGCTGGAC-3' reverse. pMIR-AKT2-MUT contained a mutated sequence in the 3'UTR of $A K T 2$ inserted into the luciferase gene in the pMIR-Reporter vector. The primers used to amplify the mutant sequences were: 5'-AAGTTATATATGCGAAACCAC CCAGCGGTGATGGCAGCGAG-3' (mutated site underlined) forward; 5'-GTGGTTTCGCATATATAACTTTTTACTTAG CCTTTTTGGTT-3' (mutated site underlined) reverse. All constructs were verified by direct sequencing by Sangon Biotech (Sangon Biotech Co. Ltd., Shanghai, China).

Dual luciferase reporter assay. The biological software Microrna (http://www.mirbase.org/) and TargetScan release 7.2 (http://www.targetscan.org/) were used to predicted as a target gene of miR-625-5p. Cells $\left(2 \times 10^{4}\right)$ were co-transfected in 96-well plates in triplicate with a firefly luciferase reporter plasmid (pMIR-AKT2-WT or pMIR-AKT2-MUT), a Renilla luciferase vector (pRL-SV40; Promega Corporation, Madison, WI, USA) and with miR-625-5p mimic or its control, using Lipofectamine $2000^{\mathrm{TM}}$. pRL-SV40 was used as a normalization control. Following $48 \mathrm{~h}$, luciferase activity was determined using a Dual Luciferase Reporter Assay System (Promega Corporation, cat. no. E1910) according to the manufacturer's protocols and was expressed as the ratio of the firefly luciferase activity to the Renilla luciferase activity.

Statistical analysis. All experiments were repeated three times. GraphPad Prism version 5 (GraphPad Software, Inc., La Jolla, CA, USA) was used to analyze the data. The data are presented as the mean \pm standard deviation for normally distributed data. A Student's t-test was used to assess the difference between two groups, while one-way analysis of variance was to analyze differences among three or more groups with a post hoc Student-Newman-Keuls test. $\mathrm{P}<0.05$ was considered to indicate a statistically significance difference.

\section{Results}

Effect of LPS on the viability of $16 H B E C s$. An MTT assay was performed to determine whether LPS influenced the viability of 16HBECs following $24 \mathrm{~h}$ of treatment with the various LPS concentrations $(0,0.1,1,10$ and $100 \mu \mathrm{g} / \mathrm{ml})$. LPS demonstrated a dose-dependent cytotoxic effect. A total of $1 \mu \mathrm{g} / \mathrm{ml}$ LPS was chosen as the best stimulatory concentration for further experiments (Fig. 1A). As presented in Fig. 1B, 16HBECs treated with LPS at $1 \mu \mathrm{g} / \mathrm{ml}$ significantly stimulated the cells' ability to secrete inflammatory cytokines compared with the control cells (IL-6 and TNF- $\alpha$; P<0.05). 16HBECs expressed a significantly increased level of miR-625-5p compared with the A549 cell line following LPS induction ( $\mathrm{P}<0.05$; Fig. 1C); therefore, 16HBECs were selected for further analysis.

Effect of miR-625-5p on LPS-induced cytokine expression. ELISA and RT-qPCR were used to confirm the association between miR-625-5p and inflammatory cytokine secretion. miR-625-5p expression was significantly increased in cells transfected with the miR-625-5p mimic $(\mathrm{P}<0.05$; Fig. 2A). miR-625-5p had no effect on the production of IL- 6 and TNF- $\alpha$ in control 16HBECs. However, the mRNA and protein levels of IL-6 and TNF- $\alpha$ were significantly decreased in miR-625-5p mimic transfected 16HBECs following LPS-induction $(\mathrm{P}<0.05$; Fig. 2B-E). Transfection with the miR-625-5p inhibitor significantly decreased miR-625-5p expression in 16HBECs when compared with the inhibitor control following LPS induction $(\mathrm{P}<0.05 ;$ Fig. 3A). Transfection with the miR-625-5p inhibitor resulted in the significantly increased expression of inflammatory cytokine mRNAs (IL- 6 and TNF- $\alpha$ ) when compared with the control in LPS treated cells $(\mathrm{P}<0.05$; Fig. $3 \mathrm{~B}$ and $\mathrm{C})$. As presented in Fig. 3D and E, inhibition of miR-625-5p expression significantly upregulated LPS-induced IL- 6 and TNF- $\alpha$ secretion.

miR-625-5p targets AKT2. The AKT2 gene was predicted as a target gene of miR-625-5p using the biological software Microrna and TargetScan. A miR-625-5p binding site was 


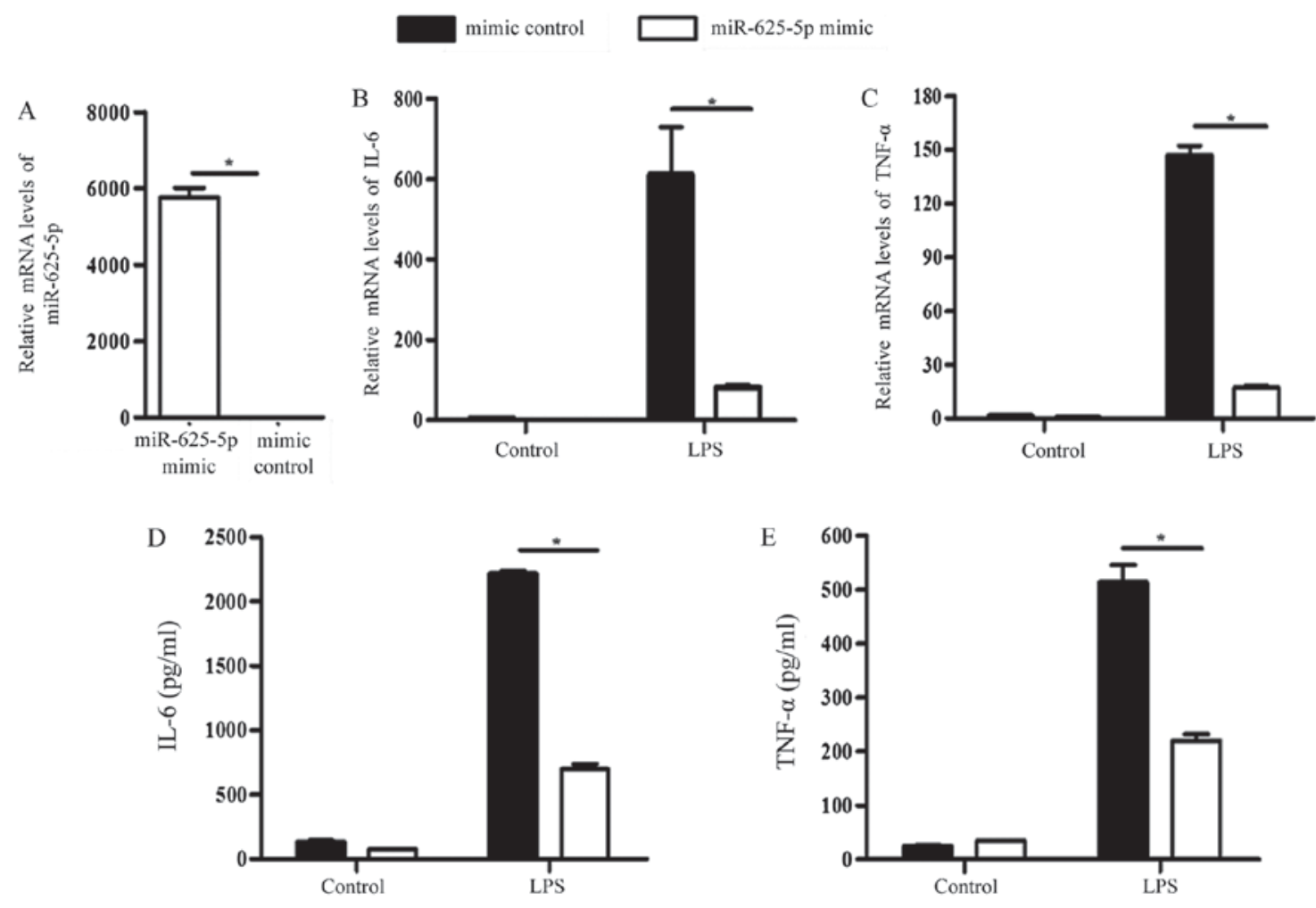

Figure 2. Expression of inflammatory cytokines in 16HBECs was determined by RT-qPCR. (A) Relative quantity of miR-625-5p following transfection of miR-625-5p mimic or its control $(50 \mathrm{nM})$ for $24 \mathrm{~h}$. 16HBECs were pretreated with miR-625-5p mimic or its control and then stimulated with $1 \mu \mathrm{g} / \mathrm{ml} \mathrm{LPS}$ for $12 \mathrm{~h}$. The expression levels of (B) IL-6 and (C) TNF- $\alpha$ mRNA were examined by RT-qPCR. The levels of (D) IL-6 and (E) TNF- $\alpha$ were evaluated in the supernatant by ELISA. "P<0.05, as indicated. LPS, lipopolysaccharide; miR, microRNA; TNF- $\alpha$, tumor necrosis factor- $\alpha$; IL, interleukin; HBEC, human bronchial epithelial cell; RT-qPCR, reverse transcription-quantitative polymerase chain reaction.

identified in the 3'UTR of $A K T 2$ (Fig. 4A). Overexpression of miR-625-5p significantly reduced the luciferase activity in cells transfected with the pMIR-AKT2-WT vector when compared with cells transfected with the pMIR-AKT2-MUT vector $(\mathrm{P}<0.05$; Fig. 4B). Western blotting was then conducted to assess the effect of miR-625-5p on the AKT2 protein level. In the miR-625-5p mimic transfected cells, the protein level of AKT2 was significantly decreased when compared with the vector only cells $(\mathrm{P}<0.05$; Fig. $4 \mathrm{C})$.

Effect of miR-625-5p on signaling pathways. AKT2 is involved in triggering the nuclear factor- $\mathrm{\kappa B}(\mathrm{NF}-\mathrm{\kappa B})$ signaling pathway and induces inflammatory cytokines (16). To investigate whether miR-625-5p influenced the regulation of the phophoinositol-3-kinase (PI3K)/AKT pathway, the levels of phosphorylated AKT2 were quantified. The level of phosphorylated AKT2 pretreatment with the miR-625-5p mimic was significantly decreased compared with LPS treatment alone ( $\mathrm{P}<0.05$; Fig. 5A). Conversely, inhibition of miR-625-5p expression significantly increased the LPS-induced phosphorylation of AKT2 $(\mathrm{P}<0.05)$. The phosphorylation/degradation of inhibitor of $\kappa \mathrm{B}(\mathrm{I} \kappa \mathrm{B} \alpha)$ is an essential step in the NF- $\kappa \mathrm{B}$ signaling pathway (17). Phosphorylation of IкB $\alpha$ was assessed to determine whether the NF- $\kappa \mathrm{B}$ signaling pathway is involved in the protective effect of miR-625-5p. The LPS-induced phosphorylation of I $\mathrm{K} \mathrm{B} \alpha$ was significantly suppressed by miR-625-5p overexpression and significantly increased by miR-625-5p inhibition compared with LPS treatment alone $(\mathrm{P}<0.05$; Fig. 5B). To further confirm whether activation of the NF- $\mathrm{BB}$ pathway was dependent on the phosphorylation of AKT2, NF- $\kappa \mathrm{B}$ activation (i.e., the phosphorylation of I $\kappa \mathrm{B} \alpha$ ) was detected in LPS-stimulated 16HBECs pretreated for $24 \mathrm{~h}$ with si-AKT2 to knockdown $A K T 2$ expression. Notably, treatment with si-AKT2 significantly inhibited the LPS-stimulated phosphorylation of IкB $\alpha(\mathrm{P}<0.05)$, which demonstrated that the PI3K/AKT axis may be involved in NF- $\mathrm{KB}$ regulation in 16HBECs (Fig. 5C).

\section{Discussion}

In the present study, it was demonstrated that miR-625-5p inhibits the secretion of inflammatory mediators in HBECs. Furthermore, AKT2 was revealed to be a direct target gene of miR-625-5p. The results indicated that miR-625-5p suppresses the airway inflammatory response by downregulating AKT2, which inhibits the NF- $\kappa \mathrm{B}$ signaling pathway. Therefore, miR-625-5p may function as an inhibitor of asthma airway inflammation by suppressing the inflammatory response in HBECs by directly targeting $A K T 2$.

Bioinformatics analysis identified that the 3'UTR of human $A K T 2$ paired miR-625-5p binding sites. The luciferase reporter assay verified the association between miR-625-5p and $A K T 2$. Furthermore, the interactions between $A K T 2$ and miR-625-5p in 16HBECs using a miR-625-5p mimic and inhibitor were demonstrated.

AKT2 is involved in insulin-mediated regulation of glucose homeostasis. However, a number of studies on AKT2 have focused on its role in tumors and demonstrated that AKT2 is 
Inhibitor control $\square$ miR-625-5p inhibitor
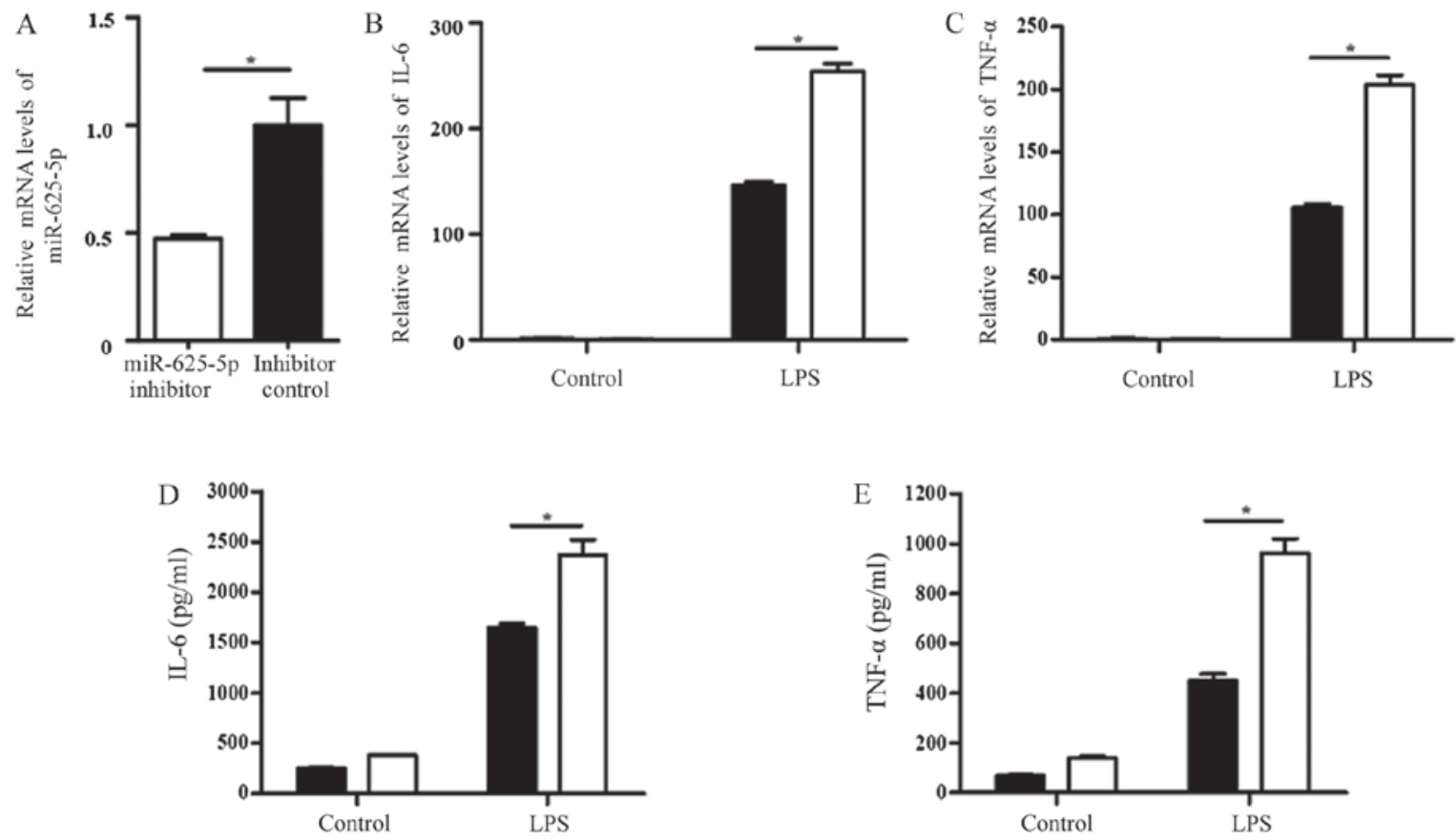

Figure 3. Expression of inflammatory cytokines in 16HBECs as determined by reverse transcription-quantitative polymerase chain reaction. (A) Relative quantity of miR-625-5p following transfection of miR-625-5p inhibitor or its control (50 nM) for $24 \mathrm{~h}$. 16HBECs were pretreated with miR-625-5p inhibitor or its control and then stimulated with $1 \mu \mathrm{g} / \mathrm{ml}$ LPS for $12 \mathrm{~h}$. The expression levels of (B) IL- 6 and (C) TNF- $\alpha$ mRNA were examined by reverse transcription-quantitative polymerase chain reaction. The levels of (D) IL- 6 and (E) TNF- $\alpha$ were detected by an ELISA. "P<0.05, as indicated. TNF- $\alpha$, tumor necrosis factor- $\alpha$; IL, interleukin; HBEC, human bronchial epithelial cell; LPS, lipopolysaccharide; miR, microRNA.
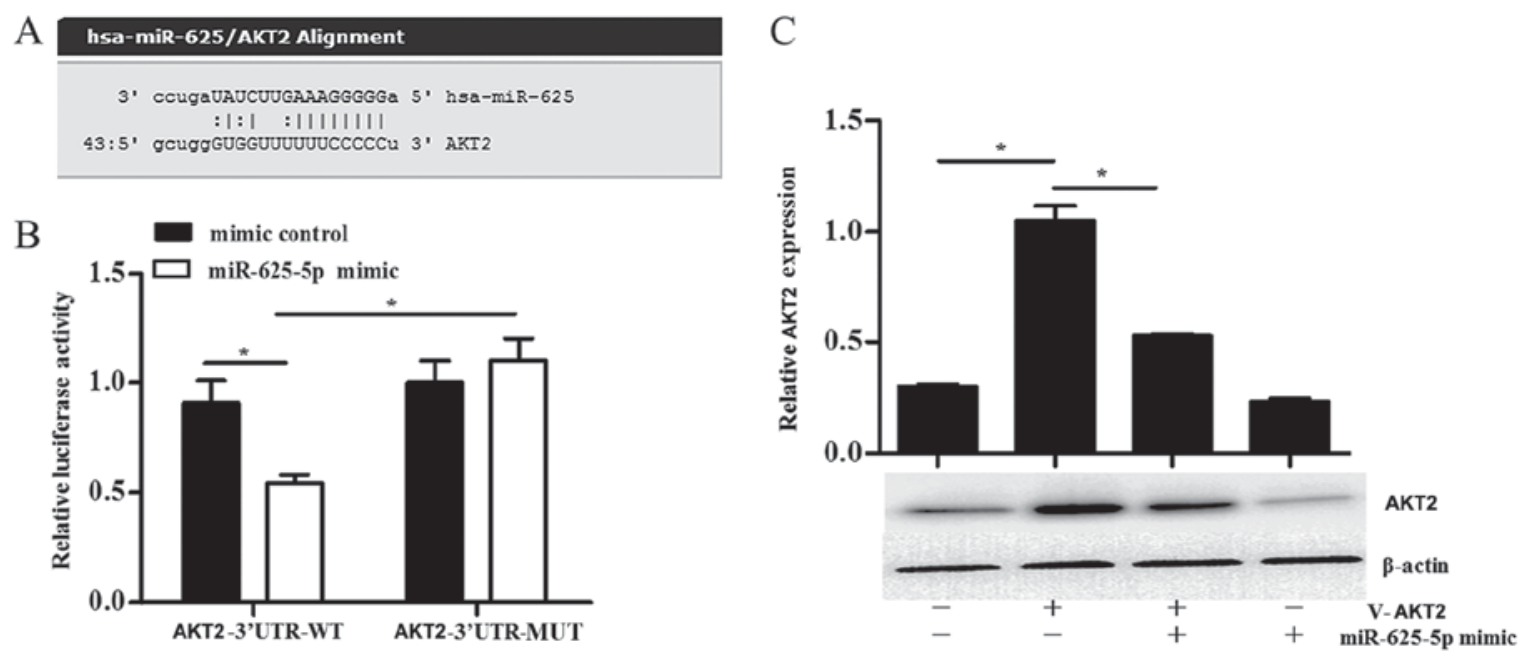

Figure 4. miR-625-5p target on AKT2 3'-UTR. (A) Analysis of miR-625-5p targeting on the 3'-UTR in the AKT2. (B) The relative luciferase activity of the 16HBECs was decreased following transfection with pMIR-AKT2-WTor pMIR-AKT2-MUT and miR-625-5p mimic or its control. (C) The protein level of AKT2 was decreased in the miR-625-5p mimic transfected cells. "P<0.05, as indicated. UTR, untranslated region; HBEC, human bronchial epithelial cell; WT, wild-type; MUT, mutant; AKT2, protein kinase B2; miR, microRNA; V, vector.

essential for tumor growth, colony formation and cancer cell proliferation, including ovarian cancer (18), breast cancer (19), and hepatocellular carcinoma (20). According to these studies, an AKT isoform has a vital role in tumor growth, colony formation and cancer cell proliferation in other lung diseases, in addition to lung tumors; however, there are contradictory results concerning its functions. Previous studies have demonstrated that AKT2 is involved in tumor growth and colony formation, and inhibiting AKT2 decreased cellular motility and migration (21-24). By contrast, another study revealed that AKT2 expression may be increased in lung tumors in a tobacco-associated model; however, loss of AKT2 expression did not lead to mutant K-ras-mediated lung tumors in a genetic model (25). In acute lung injury, Vergadi et al (26) reported that depletion of AKT2 kinase activity resulted in light acid-induced lung injury and protected mice from acid-induced lung injury (27). 
A
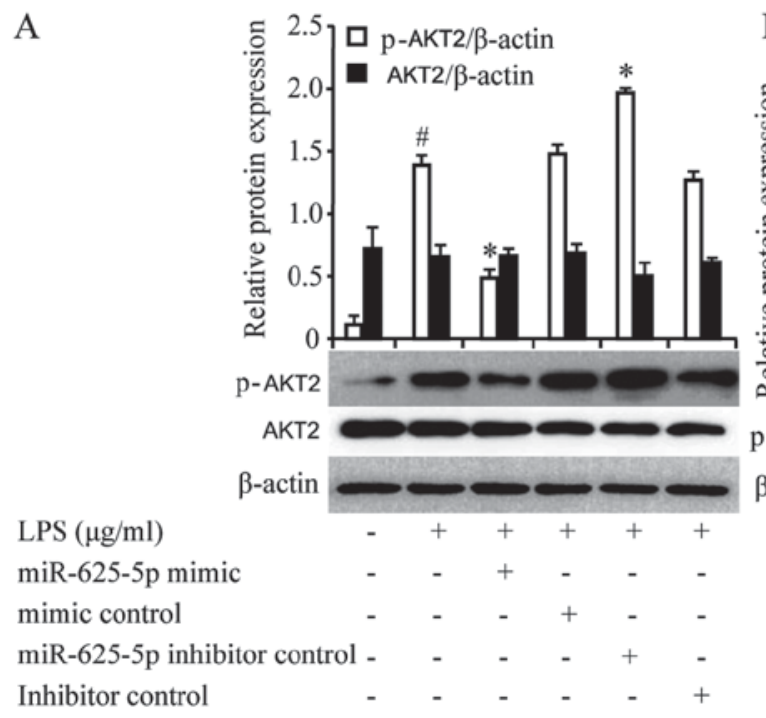

B $\quad$ C

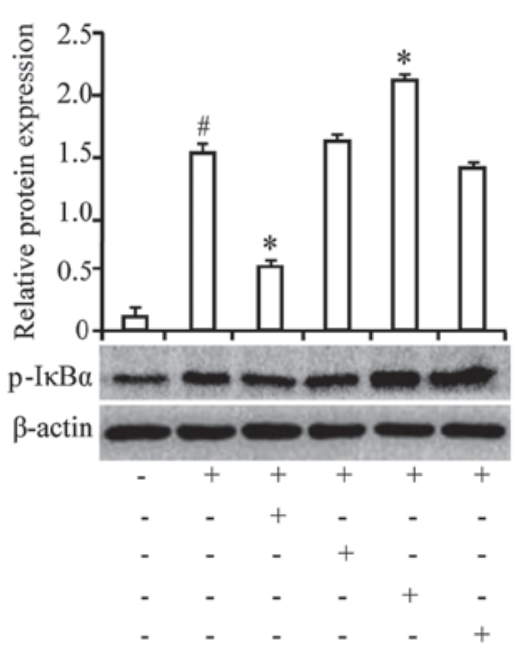

$\mathrm{C}$

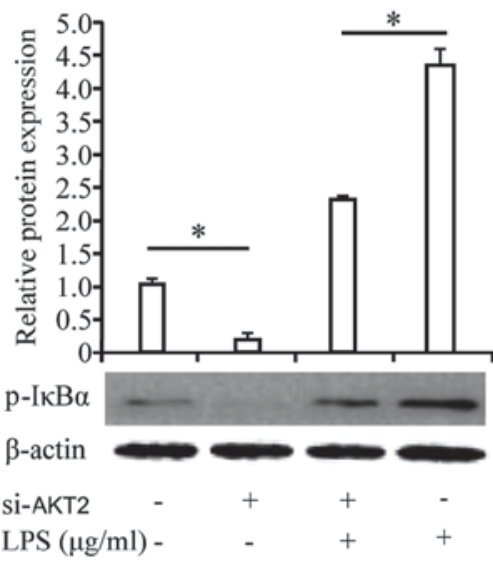

Figure 5. Role of miR-625-5p in the LPS-induced phosphatidylinositol 3 kinase/Akt signaling pathway. The phosphorylation of (A) AKT2 and (B) IкB $\alpha$ in LPS-induced cells was detected by western blot analysis following pretreatment with miR-625-5p mimic or its inhibitor compared with LPS treatment alone. ${ }^{*} \mathrm{P}<0.05$ vs. LPS; ${ }^{\text {P }}<0.05$ vs. control. (C) Cells were incubated with si-AKT $224 \mathrm{~h}$ prior to LPS treatment, then IкB $\alpha$ phosphorylation was analyzed by western blotting; ${ }^{\mathrm{P}}<0.05$, as indicated. si-AKT2, small interfering protein kinase $\mathrm{B} 2 ; \mathrm{LPS}$, lipopolysaccharide; miR, microRNA; p-, phosphorylated; I $\mathrm{B} \alpha$, inhibitor $\kappa \mathrm{B} \alpha$.

The results of the present study demonstrated that miR-625-5p inhibits the secretion of TNF- $\alpha$ and IL-6 in 16HBECs. This was in agreement with other studies $(6,28,29)$ in which the downregulation of multiple miRs, including microRNAs-18a, 21, -27a, -128 and -155 and miR-218 also resulted in the upregulation of IL-6 levels. However, a study by Jardim et al (30) confirmed that the expression of TNF- $\alpha$ was increased in asthmatic BECs, while the level of IL- 6 was downregulated compared with the samples from healthy donors. This discrepancy may have been caused by the different research methods used in the two studies. Asthma is a complex disease with a variety of phenotypes (31) and there may be two possible explanations for the discrepancy between these studies. The majority of the patients selected by Jardim et al (30) had mild asthma, whereas the present study was only an in vitro simulation that did not involve samples of asthmatic tissue. In addition, in Jardim's study, the majority of the patients with asthma were receiving medication and this may have altered the expression of certain miRs. Further study is required to determine the underlying functions of miRs in asthmatic airway inflammation, which could lead to improved diagnostic technologies and subcategorization of asthma phenotypes, ultimately leading to targeted therapies for asthma.

The results of the present study demonstrated that miR-625-5p suppresses the inflammatory response of 16HBECs by silencing $A K T 2$, which may be involved in regulating asthma. Similarly, another study revealed that the expression of miR-625-5p is markedly reduced in dust mite-induced pediatric asthma. Therefore, it has been speculated that miR-625-5p may exert protective effects in asthma (14). Indeed, lung tissue undergoes active differentiation of cells and miR-625 may serve a role in this process. Given the dysregulation of active inflammation in the asthmatic bronchi, it would not be surprising if the inaccurate differentiation of HBECs resulted in certain pathologies of asthma. In the present study, one miR targeting a single gene was focused on. However, a gene can be targeted by a number of miRs and, conversely, an miR can regulate a number of target genes. Therefore, it would be useful to characterize other miRs that may be associated with asthma to provide further options for targeted therapy. Knowledge of the function of miR-625 in inflammation is based on cell cultures. The authors' future work will demonstrate the association between miR-625 and AKT2 in murine models, which will increase our understanding of the role of miRs in asthma.

In conclusion, miR-625-5p may protect LPS-induced 16HBECs from inflammation by targeting $A K T 2$ and inhibiting the NF- $\mathrm{KB}$ signaling pathway.

\section{Acknowledgements}

Not applicable.

\section{Funding}

The project was supported by the National Natural Science Foundation of China (grant no. 81370119), and the Zhenjiang Science \& Technology Program (grant no. SH2015044).

\section{Availability of data and materials}

All data generated or analyzed during this study are included in this published article.

\section{Authors' contributions}

F-HQ and XD made substantial contributions to the design of the present study. XD, Q-XZ, BW and D-DZ performed the experiments. XD analyzed the data. F-HQ and XD wrote and revise the manuscript. All authors have read and approved the final manuscript.

\section{Ethics approval and consent to participate}

Not applicable. 


\section{Patient consent for publication}

Not applicable.

\section{Competing interests}

The authors declare they have no competing interests.

\section{References}

1. Schleimer RP, Kato A, Kern R, Kuperman D and Avila PC: Epithelium: At the interface of innate and adaptive immune responses. J Allergy Clin Immunol 120: 1279-1284, 2007.

2. Fang R, Cui Q, Sun J, Duan X, Ma X, Wang W, Cheng B, Liu Y, Hou $Y$ and Bai G: PDK1/Akt/PDE4D axis identified as a target for asthma remedy synergistic with $\beta 2 \mathrm{AR}$ agonists by a natura agent arctigenin. Allergy 70: 1622-1632, 2015.

3. Meister $\mathrm{G}$ and Tuschl T: Mechanisms of gene silencing by double-stranded RNA. Nature 431: 343-349, 2004.

4. Lu J, Getz G, Miska EA, Alvarez-Saavedra E, Lamb J, Peck D, Sweet-Cordero A, Ebert BL, Mak RH, Ferrando AA, et al: MicroRNA expression profiles classify human cancers. Nature 435: 834-838, 2005.

5. Solberg OD, Ostrin EJ, Love MI, Peng JC, Bhakta NR, Hou L, Nguyen C, Solon M, Nguyen C, Barczak AJ, et al: Airway epithelial miRNA expression is altered in asthma. Am J RespirCrit Care Med 186: 965-974, 2012.

6. Martinez-Nunez RT, Bondanese VP, Louafi F, FranciscoGarcia AS, Rupani H, Bedke N, Holgate S, Howarth PH, Davies DE and Sanchez-Elsner T: A microRNA network dysregulated in asthma controls IL-6 production in bronchial epithelial cells. PLoS One 9: e111659, 2014.

7. Matsukura S, Osakabe Y, Sekiguchi A, Inoue D, Kakiuchi Y, Funaki T, Yamazaki Y, Takayasu H, Tateno H, Kato E, et al: Overexpression of microRNA-155 suppresses chemokine expression induced by Interleukin-13 in BEAS-2B human bronchial epithelial cells. Allergol Int 65 (Suppl): S17-S23, 2016.

8. Huo X, Zhang K, Yi L, Mo Y, Liang Y, Zhao J, Zhang Z, Xu Y and Zhen G: Decreased epithelial and plasma miR-181b-5p expression associates with airway eosinophilic inflammation in asthma. Clin Exp Allergy 46: 1281-1290, 2016.

9. Haj-Salem I, Fakhfakh R, Bérubé JC, Jacques E, Plante S, Simard MJ, Bossé Y and Chakir J: MicroRNA-19a enhances proliferation of bronchial epithelial cells by targeting TGF $\beta$ R2 gene in severe asthma. Allergy 70: 212-219, 2015.

10. Rasmussen MH, Lyskjær I, Jersie-Christensen RR, Tarpgaard LS, Primdal-Bengtson B, Nielsen MM, Pedersen JS, Hansen TP, Hansen F, Olsen JV, et al: miR-625-3p regulates oxaliplatin resistance by targeting MAP2K6-p38 signalling in human colorectal adenocarcinoma cells. Nat Commun 7: 12436, 2016.

11. Kirschner MB, Cheng YY, Badrian B, Kao SC, Creaney J, Edelman JJ, Armstrong NJ, Vallely MP, Musk AW, Robinson BW, et al: Increased circulating miR-625-3p: A potential biomarker for patients with malignant pleural mesothelioma. J Thorac Oncol 7: 1184-1191, 2012.

12. Zhou X, Zhang CZ, Lu SX, Chen GG, Li LZ, Liu LL, Yi C, Fu J, Hu W, Wen JM and Yun JP: miR-625 suppresses tumour migration and invasion by targeting IGF2BP1 in hepatocellular carcinoma. Oncogene 34: 965-977, 2015.

13. Zhang J, Zhang J, Zhang J, Qiu W, Xu S, Yu Q, Liu C, Wang Y, Lu A, Zhang J and Lu X: MicroRNA-625 inhibits the proliferation and increases the chemosensitivity of glioma by directly targeting AKT2. Am J Cancer Res 7: 1835-1849, 2017.

14. Dong X, Xu M, Ren Z, Gu J, Lu M, Lu Q and Zhong N: Regulation of CBL and ESR 1 expression by microRNA-22-3p, 513a-5p and 625-5p may impact the pathogenesis of dust mite-induced pediatric asthma. Int J Mol Med 38: 446-456, 2016.
15. Livak KJ and Schmittgen TD: Analysis of relative gene expression data using real-time quantitative PCR and the 2(-Delta Delta $\mathrm{C}(\mathrm{T}))$ method. Methods 25: 402-408, 2001.

16. Ozes ON, Mayo LD, Gustin JA, Pfeffer SR, Pfeffer LM and Donner DB: NF-kappaB activation by tumour necrosis factor requires the Akt serine-threonine kinase. Nature 401: 82-85, 1999.

17. Sizemore N, Lerner N, Dombrowski N, Sakurai H and Stark GR: Distinct roles of the Ikappa B kinase alpha and beta subunits in liberating nuclear factor kappa B (NF-kappa B) from Ikappa B and in phosphorylating the p65 subunit of NF-kappa B. J Biol Chem 277: 3863-3869, 2002.

18. Linnerth-Petrik NM, Santry LA, Moorehead R, Jücker M, Wootton SK and Petrik J: Akt isoform specific effects in ovarian cancer progression. Oncotarget 7: 74820-74833, 2016.

19. Riggio M, Perrone MC, Polo ML, Rodriguez MJ, May M, Abba M, Lanari C and Novaro V: AKT1 and AKT2 isoforms play distinct roles during breast cancer progression through the regulation of specific downstream proteins. Sci Rep 7: 44244, 2017.

20. Wang Q, Yu WN, Chen X, Peng XD, Jeon SM, Birnbaum MJ, Guzman G and Hay N: Spontaneous hepatocellular carcinoma after the combined deletion of Akt isoforms. Cancer Cell 29: 523-535, 2016.

21. Attoub S, Arafat K, Hammadi NK, Mester J and Gaben AM: Akt2 knock-down reveals its contribution to human lung cancer cell proliferation, growth, motility, invasion and endothelial cell tube formation. Sci Rep 5: 12759, 2015.

22. Kim CK, Nguyen TL, Lee SB, Park SB, Lee KH, Cho SW and Ahn JY: Akt2 and nucleophosmin/B23 function as an oncogenic unit in human lung cancer cells. Exp Cell Res 317: 966-975, 2011.

23. Lee MW, Kim DS, Lee JH, Lee BS, Lee SH, Jung HL, Sung KW, Kim HT, Yoo KH and Koo HH: Roles of AKT1 and AKT2 in non-small cell lung cancer cell survival, growth, and migration. Cancer Sci 102: 1822-1828, 2011.

24. Linnerth-Petrik NM, Santry LA, Petrik JJ and Wootton SK: Opposing functions of akt isoforms in lung tumor initiation and progression. PLoS One 9: e94595, 2014.

25. Hollander MC, Maier CR, Hobbs EA, Ashmore AR, Linnoila RI and Dennis PA: Akt1 deletion prevents lung tumorigenesis by mutant K-ras. Oncogene 30: 1812-1821, 2011.

26. Vergadi E, Vaporidi K, Theodorakis EE, Doxaki C, Lagoudaki E, Ieronymaki E, Alexaki VI, Helms M, Kondili E, Soennichsen B, et al: Akt 2 deficiency protects from acute lung injury via alternative macrophage activation and miR-146a induction in mice. J Immunol 192: 394-406, 2014.

27. Gauna AE and Cha S: Akt2 deficiency as a therapeutic strategy protects against acute lung injury. Immunotherapy 6: 377-380, 2014.

28. Xu H, Sun Q, Lu L, Luo F, Zhou L, Liu J, Cao L, Wang Q, Xue J, Yang Q, et al: MicroRNA-218 acts by repressing TNFR1-mediated activation of $\mathrm{NF}-\kappa \mathrm{B}$, which is involved in MUC5AC hyper-production and inflammation in smoking-induced bronchiolitis of COPD. Toxicol Lett 280: 171-180, 2017.

29. Luo F, Xu Y, Ling M, Zhao Y, Xu W, Liang X, Jiang R, Wang B, Bian Q and Liu Q: Arsenite evokes IL-6 secretion, autocrine regulation of STAT3 signaling, and miR-21 expression, processes involved in the EMT and malignant transformation of human bronchial epithelial cells. Toxicol Appl Pharmacol 273: 27-34, 2013.

30. Jardim MJ, Dailey L, Silbajoris R and Diaz-Sanchez D: Distinct microRNA expression in human airway cells of asthmatic donors identifies a novel asthma-associated gene. Am J Respir Cell Mol Biol 47: 536-542, 2012.

31. Gauthier M, Ray A and Wenzel SE: Evolving concepts of asthma. Am J Respir Crit Care Med 192: 660-668, 2015. 